\title{
Criação, tradução e crítica: diálogos entre Berman e Proust
}

Sheila Maria dos Santos*

Les beaux livres sont écrits dans une sorte de langue étrangère Marcel Proust, Contre Sainte-Beuve

\section{Introdução}

Desde a publicação da obra canônica de Marcel Proust, À la Recherche du temps perdu (1919-1927), considerada por críticos como Antoine Compagnon (1989) e Jean-Yves Tadié (1996) como a mais importante da literatura francesa do século $X X$, sua obra tem sido objeto de milhares de estudos, em todo o mundo, assinados por críticos eminentes, tais como Walter Benjamin, Leo Spitzer, Curtius, Erich Auerbach, Samuel Beckett, Blanchot, Deleuze, Derrida, Kristeva, entre outros, focalizando os aspectos mais variados de sua composição. Com efeito, conforme declara Compagnon, "Sur Proust, on a écrit tout et n'importe quoi" (1992, p. 54); de opinião semelhante é Thomas Carrier-Lafleur, quando este afirma que "On dit que tout a été dit sur Proust, mais en même temps rien n'a été dit. Relire Proust, c'est le réécrire" (2010, p. 425). Assim, ciente da complexidade da tarefa que é apresentar algo novo sobre Proust, pretendo, por minha vez, acrescentar mais um grãozinho de areia a este imenso mar da crítica proustiana, explorando suas concepções teóricas sobre criação, tradução e crítica em diálogo com as contribuições do teórico da tradução Antoine Berman.

Ainda que Marcel Proust seja um dos autores mais estudados do século $\mathrm{XX}$, a grande maioria dos trabalhos críticos proustianos volta-se para sua obra maior, a Recherche, desconsiderando, muitas vezes, uma vasta

${ }^{*}$ Universidade Federal de Santa Catarina (UFSC) 
produção bibliográfica do autor. Por isso, propus-me a investigar vias pouco exploradas, como, por exemplo, sua atuação como tradutor e crítico literário, sob um viés comparatista. Para tanto, parto de sua experiência tradutória, enquanto tradutor das obras La Bible d'Amiens (1904) e Sésame et les lys (1906), de John Ruskin, com foco nos paratextos dessas traduções, onde Proust apresenta uma extensa reflexão crítica sobre sua prática tradutória, mas também sobre a função da crítica literária, sobre os limites entre criação, tradução e crítica, sobre a função da leitura e do leitor, entre outras questões ali presentes, as quais deixarei de lado para não me distanciar do foco do artigo.

Antoine Berman, por sua vez, é um dos teóricos mais eminentes dos Estudos da Tradução e da Tradutologia no século XX, e suas contribuições ainda hoje são constantemente utilizadas em trabalhos acadêmicos, sobretudo no que diz respeito à crítica de tradução literária, foco de sua atenção em obras como Pour une critique des traductions: Johnn Donne (1995) e La traduction et la lettre ou l'auberge du lointain (1985), entre outras. Aliás, a esse respeito, Maurício Cardozo afirma que "é provável que a obra contemporânea mais importante para a discussão dos limites e das possibilidades da crítica de tradução literária seja Pour une critique des traductions: John Donne" (CARDOZO, 2015, p. 250).

Assim, tomando como base os escritos de Marcel Proust e Antoine Berman, buscarei elucidar algumas confluências conceituais caras aos Estudos da Tradução, bem como à Literatura, de modo geral. A escolha por tal aproximação não é arbitrária, uma vez que Marcel Proust é citado em todos os livros de Antoine Berman, reiteradas vezes em algumas obras, como é o caso de La traduction et la lettre ou l'auberge du lointain (1985), em que o nome de Proust aparece doze vezes, tornando possível estabelecer esses diálogos. É importante ressaltar que o conceito de "diálogo" aqui utilizado não está, evidentemente, atrelado à ideia de um diálogo entre interlocutores, mas sim entre discursos, portanto, na linha desenvolvida por Bakhtin (1986). 


\section{Criação, tradução e crítica: diálogos entre Berman e Proust}

Proust estreia na literatura com a publicação de Les plaisirs et les jours (1896), coletânea de poemas em prosa, com prefácio de Anatole France, publicado pela Calmann-Lévy. Data dessa mesma época a redação de Jean Santeuil, livro conhecido como a gênese da Recherche, publicado postumamente, em 1952. No início do século XX, o autor faz uma incursão na tradução, motivado por seu apreço pelos escritos do célebre crítico de arte, escritor e desenhista britânico John Ruskin (1819-1900), e decide traduzir duas obras de sua autoria, a saber, La Bible d'Amiens (1904) e Sésame et les lys (1906). É possível encontrar diversos textos de crítica de tradução voltados ao cotejo da tradução feita por Proust da obra de Ruskin, sobretudo focando em questões de ordem linguística, com vistas a "desmascarar" Proust, buscando expor seu desconhecimento da língua inglesa e suas implicações textuais. Um caso emblemático é o do texto de Alphonse Roche, "Proust as a Translator of Ruskin" (1930), em que o autor acusa Proust de ser um péssimo tradutor e cometer uma série de erros gramaticais inaceitáveis. No entanto, aqui, busco tomar outra via, menos explorada, menos normativa e menos voltada ao que Berman chama de crítica negativa (1995), aquela que seguiria a linha de Meschonnic. Antes, será o caso de explorar conceitualmente os prefácios às traduções de Ruskin, que se tornaram famosos textos de crítica sobre a obra desse autor, com vistas à identificação de ecos que ressoam nas obras de Berman.

La Bible d'Amiens, publicada em 1904, pela Mercure de France, possui um prefácio do tradutor dividido em quatro partes: I -Avant-propos; II Ruskin à Notre-Dame d'Amiens; III - John Ruskin; IV - Post-scriptum. É curioso notar a dimensão do prefácio do tradutor, em comparação com a tradução em si, que representa cerca de um terço da obra, com 95 páginas, sendo que apenas o p.s. possui dez páginas. Ora, ainda que esta opulência verbal seja marca característica do estilo proustiano, está longe de ser prática corrente entre tradutores, o que representa o primeiro choque ao tomarmos conhecimento da obra. Com isso, trago a primeira questão que gostaria de abordar aqui, a visão da tradução e do tradutor, segundo Proust e Berman.

Proust traduziu essa obra na virada do século $X X$, portanto, em uma época em que a tradução ainda era vista como um mal necessário, e o 
tradutor, como um agente invisível. Com efeito, ao responder a pergunta "Proust est-il un traducteur comme les autres ?", Tadié afirma que não, pelo fato de Proust não estar alinhado à prática corrente francesa: “Or une longue tradition, depuis la Renaissance et les 'belles infidèles' du XVIIe siècle, permettait aux traducteurs français de donner une version bien éloignée de l'original" (TADIÉ, 1996, p. 729-730). E segue explicando que:

\footnotetext{
Proust, au contraire, cherche l'épithète juste, colle au sens, au rythme et à la musique de la phrase: c'est ainsi que l'usage du contraste, de l'oxymore, ou bien l'accumulation de qualificatifs, l'usage de trois adjectifs appartenant à des domaines différents figurent chez les deux écrivains. Marcel l'imite d'ailleurs dans son pastiche de Ruskin. (TADIÉ, 1996, p. 731)
}

Portanto, é possível identificar um tradutor que não pretende realizar uma tarefa puramente linguística e servil, tampouco pretende agradar ao público-leitor; sua responsabilidade, segundo o autor, é tão somente com o texto de Ruskin e sua interpretação da obra:

\begin{abstract}
Le texte traduit ici est celui de La Bible d'Amiens in extenso. Malgré les conseils différents qui m'avaient été donnés et que j'aurais peut-être dû suivre, je n'en ai pas omis un seul mot. Mais ayant pris ce parti, pour que le lecteur pût avoir de la Bible d'Amiens une version intégrale, je dois lui accorder qu'il y a bien des longueurs dans ce livre comme dans tous ceux que Ruskin a écrits à la fin de sa vie. De plus, dans cette période de sa vie, Ruskin a perdu tout respect de la syntaxe et tout souci de la clarté, plus que le lecteur ne consentira souvent à le croire. Il accusera alors très injustement les fautes du traducteur. (PROUST, 1904, p. 13)
\end{abstract}

Ao declarar sua posição face ao texto e seu desejo de respeitar a sintaxe e o ritmo da obra, Proust antecipa a reação do leitor, afirmando que este o acusará muito injustamente de ter cometido tais faltas. Não obstante, a previsão de uma reação negativa por parte do leitor diante de seu parti pris não o faz mudar seu projeto tradutório, alinhando-se, com isso, ao que Berman chamou de objetivo ético do traduzir (1999, p. 77). No entanto é curioso notar que ao mesmo tempo em que o escritor-tradutor adverte ter 
seguido de perto a escrita ruskiniana, afirma que isso não é suficiente, e justifica:

\footnotetext{
Je donne ici une traduction de la Bible d'Amiens, de John Ruskin. Mais il m'a semblé que ce n'était pas assez pour le lecteur. (...) En mettant une note en bas du texte de La Bible d'Amiens, chaque fois que ce texte éveillait par des analogies, même lointaines, le souvenir d'autres ouvrages de Ruskin, et en traduisant dans la note le passage qui m'était ainsi revenu à l'esprit, j'ai tâché de permettre au lecteur de se placer dans la situation de quelqu'un qui ne se trouverait pas en présence de Ruskin pour la première fois, mais qui, ayant déjà eu avec lui des entretiens antérieurs, pourrait, dans ses paroles, reconnaître ce qui est, chez lui, permanent et fondamental. Ainsi, j'ai essayé de pourvoir le lecteur comme d'une mémoire improvisée où j'ai disposé des souvenirs des autres livres de Ruskin. (PROUST, 1904, p. 9-10)
}

Esse trecho é particularmente emblemático, pois traz à tona a memória, tema que se tornaria, anos mais tarde, o fio condutor da Recherche. Compagnon afirma que um clássico é uma obra que todo mundo conhece, mas que ninguém leu (2011), e cita Proust como exemplo maior dessa prática, que consiste em travar conhecimento com textos críticos sobre determinada obra e assim depreender características do estilo do autor sem tê-lo lido diretamente. Nesse sentido, cita a questão das frases longas, tipicamente proustianas, bem como a memória, tema central da Recherche, explorada através do conceito de memória involuntária, responsável por estruturar as passagens mais simbólicas da obra, como o famoso episódio das madeleines. Aqui, na qualidade de tradutor, Proust nos fala de uma "memória improvisada", que, diferentemente da memória involuntária, responsável por "enganar o tempo" e nos trazer uma sensação do passado que sempre esteve conosco e apenas necessitava de um gatilho para irromper à superfície, não parte do leitor, mas sim do tradutor, que lhe "força" lembranças do que não conhecemos. Proust, quando julga necessário, explicita ao leitor seu trajeto analítico, suas impressões sobre a obra, sobre o autor, transferindo para a tradução, e para o leitor, a sua memória de leitura.

Com isso, nos apresenta uma visão sobre a tradução que não é diferente da crítica literária, tampouco da criação poética, uma vez que o 
autor enxerga essas tarefas como análogas, frutos de uma mesma matriz: a Literatura. A esse respeito, Antoine Berman afirma:

\begin{abstract}
Il est vrai qu'il faut tenir à la traduction restreinte (inter-langues), en tant que c'est là, rigoureusement parlant, qu'il y a de la traduction. Cependant, cela ne doit pas nous empêcher d'écouter et le parler courant (quand il emploie "métaphoriquement" le terme de traduction, ce qui se fait tous les jours), et toute une lignée d'écrivains et de penseurs, de Hamann à Proust, Valéry, Roa Bastos, Pasternak, Marina Tsvétaïeva, etc. pour qui la traduction signifie non seulement le «passage » interlangues d'un texte, mais - autour de ce premier "passage» - toute une série d'autres « passages » qui concernent l'acte d'écrire et, plus secrètement encore, l'acte de vivre et de mourir. (BERMAN, 1999, p. 20)
\end{abstract}

Esse tema também aparece em L'Épreuve de l'étranger, em que Berman afirma que "Novalis et A. W. Schlegel, mais aussi Baudelaire, Proust et Valéry, ont eu l'intuition de ce rapport 'consubstantiel' entre les 'lettres' et la traduction. Ils ont même été jusqu'à affirmer que l'opération de l'écrivain et celle du traducteur étaient identiques" (BERMAN, 1984, p. 295). Mas, para Proust, a relação não é dicotômica, não se limita a duas operações, criação e tradução. Sua concepção sobre tais práticas parte, antes, de um trabalho crítico que nasce na leitura. Antes de escrever, traduzir, criticar, é preciso ler, uma vez que é a formação do leitor que o habilita a tais práticas. Sem leitura não há criação. Sem leitura não há tradução. Não há memória. Não há senso crítico. E não coincidentemente, a leitura é tema de outro prefácio à tradução de Ruskin, Sésame et les lys (1906), intitulado "Sur la lecture", posteriormente publicado como livro independente, atestando de seu valor crítico universal, seguindo caminho semelhante ao célebre texto de Benjamin sobre a tarefa do tradutor, inicialmente prefácio à tradução de Baudelaire.

Muntaner afirma que "la traduction est la manière la plus parfaite, la plus complète de lire" (1993, p. 639). Proust, por sua vez, dirá o inverso. A leitura, tema caro a Proust, não aparece apenas no prefácio à tradução, mas transparece em todos os seus textos críticos, seus pastiches, suas obras, disposta como pedra angular. Segundo Tadié, o autor nos apresenta em sua tradução: 


\begin{abstract}
Une véritable philosophie de la critique et de la lecture qu'il nous découvre. La première partie de toute critique consiste à pourvoir le lecteur d'une mémoire improvisée. Celle-ci dépasse la dispersion du temps de la lecture, reconstruit l'œuvre autour de deux passages, deux moments, en fait jaillir un instant intemporel. (TADIÉ, 1996, p. 614)
\end{abstract}

Até então, vimos que Proust não diferencia criação e tradução, tomadas pelo autor como práticas idênticas, como declara na célebre passagem do Temps retrouvé: “le seul livre vrai, un grand écrivain n'a pas, dans le sens courant, à l'inventer puisqu'il existe déjà en chacun de nous, mais à le traduire. Le devoir et la tâche d'un écrivain sont ceux d'un traducteur" (1927, p. 41). No entanto, Berman adverte que "il convient de marquer les limites de cette identification si typiquement romantique" (1984, p. 295), recordando os limites entre tais práticas, que seria, segundo o teórico, a relação entre original e tradução, ou seja, a existência de um texto referencial: “Toute traduction n'a de sens que comme traduction d'un original. La Littérature, elle, ne connaît aucun rapport de ce genre, même si elle en a la nostalgie" (BERMAN, 1984, p. 295).

Passemos, agora, à relação entre crítica e tradução. Para tanto, cito mais um trecho do prefácio à tradução de La Bible d'Amiens, em que Proust afirma que "Au fond, aider le lecteur à être impressionné par ces traits singuliers, placer sous ses yeux des traits similaires qui lui permettent de les tenir pour les traits essentiels du génie d'un écrivain, devrait être la première partie de la tâche de tout critique" (PROUST, 1904, p. 10). Conforme dito, esse trecho é retirado do "prefácio do tradutor", porém, vemos que Proust discorre sobre a "tarefa de todo crítico". É comum, ao longo do texto, identificarmos esse deslocamento lexical/conceitual operado por Proust ao justificar sua tradução, sempre na qualidade de "crítico" ou de "escritor". Não é errôneo afirmar, portanto, que para Proust a tradução é, antes de mais nada, um trabalho crítico, além de um laboratório de escrita, conforme relembra Tadié ao afirmar que "Proust, discutant l'esthétique de Ruskin, y découvre la sienne propre. Le premier caractère de la grande œuvre est d'être non pas personnelle, mais universelle" (TADIÉ, 1996, p. 618-619). O autor ainda insere Proust numa certa tradição entre escritores: 


\begin{abstract}
De même que Baudelaire et Mallarmé avaient traduit Poe et que, dans sa génération, Gide transposerait Shakespeare, Conrad, Tagore, que Claudel adaptait Conventry Patmore, Valéry Virgile, Larbaud, Samuel Butler, Proust, comme eux, voulait révéler un auteur et sentait que la traduction était une merveilleuse école de style. (TADIÉ, 1996, p. 517).
\end{abstract}

A crítica literária era tarefa tão cara a Proust que o autor estabeleceu distintas formas de praticá-la, sendo a tradução (interlingual) apenas uma delas. Para explorar esse assunto, proponho uma distinção inicial entre o que chamo que crítica ficcional e não ficcional. Com essa distinção pretendo abarcar no quadro crítico proustiano os seus pastiches, os quais enquadro na categoria de crítica ficcional. O livro Pastiches et mélanges (1919) é perfeito para explicar os dois tipos de crítica proustiana, pois apresenta essa divisão desde seu título. A primeira parte, como o nome indica, é composta pelos pastiches, unidos pelo tema central, L'Affaire Lemoine. Aqui se encontra o que chamo de crítica ficcional, pois, à diferença da tradução, o pastiche não busca imitar um texto, mas sim um estilo, portanto, parte da criação críticoliterária. Segundo Berman, "L'imitation et sa forme mineure, le pastiche, sont les modes les plus proches de l'acte de traduire. (...) Les pastiches de Proust sont des modèles du genre" (BERMAN, 1999, p. 36). Proust afirma que "Par paresse de faire de la critique littéraire, amusement de faire de la critique littéraire 'en action'1". O que chama de crítica en action é, com efeito, um complexo trabalho crítico feito sobre uma série de obras do mesmo autor, em busca das qualidades diferenciais desse autor, as quais pretende reproduzir através de uma narrativa inventada. Os pastiches possuem como mote comum o caso de Lemoine, que afirmara ter descoberto o segredo da fabricação de diamantes e recebera uma fortuna de investidores, que caíram no golpe do vigarista. E afirma que "cette insignifiante affaire de police correctionnelle, mais qui passionnait alors l'opinion, fut choisie un soir par moi, tout à fait au hasard, comme thème unique de morceaux, où j'essayerais d'imiter la manière d'un certain nombre d'écrivains" (PROUST, 1919, p. 11).

Ao total são nove pastiches, nos quais o autor busca reproduzir traços do estilo de Balzac, Flaubert, Henri de Régnier, os irmãos Goncourt,

\footnotetext{
${ }^{1}$ Carta de 17 de março de 1908, a Robert Dryfus, em Marcel Proust, Correspondance, vol. VIII, 1981, p. 61.
} 
Michelet, Faguet, Renan e Saint-Simon, além de uma crítica do romance de Flaubert sobre o caso Lemoine supostamente escrita por Sainte-Beuve, seu inimigo teórico. Ora, não é preciso muito para imaginar a complexidade de tal atividade intelectual, uma vez que sua amplidão exige um trabalho de leitura crítica global da obra do autor, além de talento literário para reproduzir tais características, sob a forma de um texto literário que faça o leitor identificar o "autor por trás do autor". Ou seja, ao lermos o pastiche de Balzac não devemos identificar traços da escrita proustiana, mas sim da balzaquiana. Esse movimento de imitação de um estilo, que é próprio do pastiche, é muito próximo do discurso tradicionalmente ouvido por parte de tradutores que buscam reproduzir um estilo, em um texto que "não pareça uma tradução", cujo objetivo é produzir um texto que supostamente diz o que determinado(a) autor(a) diria se tivesse nascido em tal país e falasse tal língua. Com efeito, os limites entre tradução, imitação e pastiche são muito tênues, como afirma Antoine Berman ao dizer que "Pour une analyse stylistique, en tout cas, imitation, pastiche et traduction sont formellement presque indiscernables" (BERMAN, 1999, p. 37). Proust explica, no prefácio à tradução da Bible d'Amiens, portanto, discorrendo sobre sua prática tradutória, o princípio do pastiche:

\begin{abstract}
Or, en causant une fois avec une personne, on peut discerner en elle des traits singuliers. Mais c'est seulement par leur répétition, dans des circonstances variées, qu'on peut les reconnaître pour caractéristiques et essentiels. Pour un écrivain, pour un musicien ou pour un peintre, cette variation des circonstances qui permet de discerner, par une sorte d'expérimentation, les traits permanents du caractère, c'est la variété des œuvres. (PROUST, 1904, p. 9)
\end{abstract}

Embora Proust esteja falando sobre a importância das notas que dispôs ao longo de sua tradução, explicitando ligações com outros textos de Ruskin, o trecho é particularmente pertinente à discussão sobre seus pastiches, pois parte do mesmo princípio, corroborando a declaração de Berman sobre os limites entre tais práticas. No que tange às notas do tradutor, álias, Tadié afirma que "l'essentiel pour lui, était le commentaire, notes et préface" (TADIÉ, 1996, p. 632). Tadié ainda recorda a natureza 
enciclopédica das notas e sua importância na tradução, uma vez que muitas vezes ocupa mais espaço na página do que a própria tradução: “La note, qui occupe souvent plus de place sur la page que le texte lui-même, est un exercice d'exhaustivité, d'encyclopédisme. Dans la Recherche, Proust développe encore ce souci" (TADIÉ, 1996, p. 613).

Ainda a respeito dos pastiches, enquanto Berman os aproxima da tradução, Jean-Yves Tadié identifica sua estreita relação com a crítica literária, conforme é possível perceber no trecho em que afirma que: “Le pastiche reconstitue en le condensant ce qu'il a senti en lisant les œuvres de ses maîtres; la critique analyse clairement la technique de ces écrivains, de sorte que pastiches et critique se complètent" (TADIÉ, 1996, p. 57-58). Assim, partindo dessas duas perspectivas complementares é possível identificar como denominador comum dessas práticas a crítica literária. Antoine Berman afirma que:

\footnotetext{
Tout traducteur entretient un rapport spécifique avec sa propre activité, c'est-à-dire a une certaine "conception" ou "perception" du traduire, de son sens, de ses finalités, de ses formes et modes. "Conception" et "perception" qui ne sont pas purement personnelles, puisque le traducteur est effectivement marqué par tout un discours historique, social, littéraire, idéologique sur la traduction (et l'écriture littéraire). La position traductive est, pour ainsi dire, le "compromis" entre la manière dont le traducteur perçoit en tant que sujet pris par la pulsion de traduire, la tâche de la traduction, et la manière dont il a "internalisé" le discours ambiant sur le traduire (les "normes") (BERMAN, 1995, p. 74)
}

Portanto, concordando com Antoine Berman sobre a posição tradutiva ser um reflexo da visão do tradutor sobre sua tarefa, podemos afirmar que a posição tradutiva de Proust se assemelha, ou reproduz, a sua visão sobre a crítica literária, bem como sobre a criação poética. Nesse mesmo texto, Berman adverte que "Ce qui est important à noter, c'est que critique et traduction sont structurellement parentes" (BERMAN, 1995, p 40), levando-nos a aproximar a visão de Proust e Berman sobre tais práticas. A esse respeito, ainda, Antoine Berman é categórico e afirma que "Le traducteur agit en critique à tous les niveaux" (BERMAN, 1995, p. 40). 
Finalmente, gostaria de explorar um último aspecto da posição tradutiva proustiana apontado por Berman em sua obra L'Âge de la traduction: "La tâche du traducteur" de Walter Benjamin, un commentaire (2008):

\begin{abstract}
Il existe un lien d'essence entre traduction et commentaire remontant (sans $\mathrm{s}^{\prime} \mathrm{y}$ limiter) à la tradition philosophique et théologique (ou religieuse). Tout commentaire d'un texte étranger comporte un travail de traduction. A la limite, est traduction. Inversement, toute traduction comporte un élément de commentaire, comme on peut le voir avec les "translations" médiévales. Un bel exemple de traduction et de commentaire entrelacés nous est donné par la version que Proust a faite de Ruskin, où le texte traduit s'accompagne, page après page, de remarques de toutes sortes. Ce travail de Proust (par ailleurs des plus subjectifs) nous rappelle quelque chose que nous avons presque oublié. (BERMAN, 2008, p. 18)
\end{abstract}

Conforme declara Antoine Berman, Proust retoma o laço essencial entre tradução e comentário, cujo resultado é uma tradução que eleva seu caráter crítico à sua realização extrema pela via do comentário, que, muitas vezes, ocupa mais lugar na página do que a tradução em si. Aliás, Berman reforça a importância da restauração do laço entre tradução e comentário: "L'autonomisation du discours 'critique' a brisé ce vieux lien de la traduction et du commentaire, et il nous paraît souhaitable de le réinstaurer" (BERMAN, 2008, p. 18). Ao explorar o caráter religioso do comentário, Berman afirma que:

\footnotetext{
Commentaire (non-traduction) et traduction sont religieux par essence. Cela ne veut pas dire que le traducteur ait des quelconques convictions religieuses de type dogmatique et orthodoxe, mais que dans sa tâche, il est aux prises avec la lettre de l'œuvre. Dans la traduction de la lettre de l'œuvre sacrée, sa propre langue subit une mutation décisive qui l'emporte au-delà d'elle-même, avec un point de non-retour à ce qu'elle était avant. Dans la vie d'une langue, la traduction d'un texte sacré marque une césure. Cela veut dire: la langue traduisante devient religieuse. Ou encore: la lettre étrangère réceptacle $d u$ "sacré » s'imprime en elle, la marque de son empreinte. Par la traduction, elle devient "vase » et "réceptacle" d'une "parole" qui est à la fois toute entière contenue dans la langue d'origine et ne cesse de vouloir en déborder. (BERMAN, 2008, p. 130)
} 
Contudo, não se trata de religiosidade como a entendemos. Segundo Berman, "Il faudrait parvenir à penser assez précisément le concept de 'religiosité' pour pouvoir y inclure des œuvres comme celles de Kafka, Broch, Proust, Rilke, George, Freud ou Guimarães Rosa, ou Tolstoï et Dostoïevski, ou Racine, ou Diderot, Goethe etc. " (BERMAN, 2008, p. 130). De opinião semelhante é Jean-Yves Tadié, ao afirmar que "Proust gardera le divin sans la religion" (TADIÉ, 1996, p. 619), quando discute as traduções de Proust. Retomo Berman, que conclui, a esse respeito, que se conseguíssemos redefinir o conceito de religiosidade, chegaríamos à conclusão de que traduzir grandes obras é sempre um ato religioso².

\section{Considerações finais}

Após identificar uma presença constante de Proust nos escritos de Antoine Berman, surgiu o interesse em explorar essa ligação. Para tanto, e em decorrência da complexidade da tarefa, decidi estabelecer como categorias de análise alguns conceitos caros aos Estudos da Tradução, bem como à Literatura de modo geral, a saber, a criação, a tradução e a crítica. No que compete à bibliografia proustiana, baseei-me, sobretudo, nos paratextos das traduções que realizou das obras de John Ruskin, La Bible d'Amiens (1904) e Sésame et les lys (1096), uma vez que esses textos apresentam rico material sobre tais práticas e permitem o estabelecimento do diálogo aqui proposto com as obras de Antoine Berman.

A partir dessa análise comparativa, foi possível depreender algumas confluências entre a visão de Proust sobre tais práticas e a de Antoine Berman, atestando a modernidade do pensamento de Proust sobre a tradução. Como vimos, Marcel Proust não distinguia criação, tradução e crítica, práticas vistas pelo autor como análogas e realizadas com o mesmo objetivo: apresentar um escritor ao público, mesmo que esse autor seja si próprio, no caso da criação. Além disso, Proust insiste em apontar a origem comum de tais práticas, a saber, a leitura. Para o autor, todo ato criativo parte

\footnotetext{
2 "Si nous y parvenions, nous arriverions à cette conclusion que traduire, traduire de grandes œuvres, est toujours acte religieux où nous amenons la langue à mûrir. Pas seulement à s'élargir, s'enrichir, s'affiner (catégories profanes), mais à pénétrer plus avant dans le secret de sa vie propre, et de sa vie orale la plus profonde" (BERMAN, 2008, p. 130).
} 
de uma leitura profunda e diversa de textos, mas também de experiências, como elucida em Sur la lecture (1906), estabelecendo origens comuns entre criação, tradução e crítica. Embora Berman advirta sobre os limites do que chamou de uma definição romântica da tradução, o teórico considera válida a visão de alguns escritores, dentre os quais se encontra Marcel Proust, sobre a tradução vista como criação, além de expor a importância de resgatar o elo entre tradução e comentário, que é a base da prática tradutória proustiana, bem como de sua obra maior, $\grave{A}$ la Recherche du temps perdu, que se constitui a partir de comentários e impressões do Narrador. Outrossim, busquei elucidar nesse artigo a importância dada pelo escritor ao trabalho crítico, praticado tanto em suas criações poéticas, quanto através das traduções e comentários, pastiches, além da crítica em sua forma tradicional, mais uma vez desestabilizando fronteiras e convidando-nos a repensá-las.

\section{Referências bibliográficas}

BAKHTIN, Mikhail Mikhailovich. Marxismo e filosofia da linguagem: problemas fundamentais do método sociológico na ciência da linguagem. Tradução Michel Lahud e Yara Frateschi Vieira, com a colaboração de Lucia Teixeira Wisnik e Carlos Henrique D. Chagas Cruz. 3aㅡ ed. São Paulo: Hucitec, 1986.

BERMAN, Antoine. Jacques Amyot, traducteur français: Essai sur les origines de la traduction en France. Paris: Belin, 2012.

BERMAN, Antoine. L'épreuve de l'étranger. Paris, Gallimard, 1984.

BERMAN, Antoine. Pour une critique des traductions: John Donne. Paris: Gallimard, 1995.

BERMAN, Antoine. La traduction et la lettre ou l'auberge du lointain (1985). Paris: Seuil, 1999.

BERMAN, Antoine. L'Âge de la traduction: "La tâche du traducteur" de Walter Benjamin, un commentaire. Saint-Denis: PUV, 2008.

CARDOZO, Mauricio Mendonça. Tradução \& os sentidos da crítica. In: AMORIM, L. M.; RODRIGUES, C. C.; STUPIELLO, E. N. A. (orgs.). Tradução 
\&: perspectivas teóricas e práticas [online]. São Paulo: Editora UNESP; São Paulo: Cultura Acadêmica, 2015, p. 233-262.

COMPAGNON, Antoine. Proust entre deux siècles. Paris: Seuil, 1989.

COMPAGNON, Antoine. Ce qu'on ne peut plus dire de Proust. Littérature, n. 88, 1992. Formes et mouvement - Proust éditions et lectures, p. 54-61.

COMPAGNON, Antoine. Le classique. 2011, p. 1-10. Disponível em: http://www.college-de-france.fr/site/antoine-

compagnon/articles en ligne.htm

KOLB, Philip. Proust et Ruskin; nouvelles perspectives. In: Cahiers de l'Association internationale des études françaises, $n^{\circ} 12$, p. 259-273, 1960.

PROUST, Marcel. À la recherche du temps perdu. Paris: Nouvelle Revue Française, 1919-1927.

PROUST, Marcel. Préface du traducteur. In: RUSKIN, J. La Bible d'Amiens. Traduit par Marcel Proust. Paris: Société Mercure de France, 1904, p. 9-47.

PROUST, Marcel. Préface du traducteur: Sur la lecture. In: RUSKIN, J. Sésame et les lys. Traduit par Marcel Proust. Paris: Mercure de France, 1906, p. 5-58.

PROUST, Marcel. Pastiches et mélanges. Paris: NRF, 1919.

PROUST, Marcel. Contre Sainte-Beuve. Paris: Gallimard, 1954.

ROCHE, Alfonse J. Proust as a translator of Ruskin. Modern Language Association, v. 45, n. 4, s/l, p. 1214-1217, 1930.

TADIÉ, Jean-Yves. Marcel Proust: biographie I. Paris: Gallimard, 1996.

\section{Resumo}

Pretende-se, neste trabalho, refletir acerca de conceitos fundamentais para os Estudos da Tradução, bem como para a Literatura de modo geral, a saber, a criação, a tradução e a crítica, sob a ótica de Antoine Berman e Marcel Proust. Por se tratar de figuras emblemáticas em suas respectivas áreas, as quais são interdependentes, suas concepções apresentam uma certa canonicidade e circulam de maneira expressiva no meio literário. Embora os escritos de 
Proust e Berman possuam cerca de oitenta anos de distanciamento temporal, é possível identificar uma série de confluências conceituais que atestam a modernidade do pensamento de Proust sobre a prática tradutória, além de apresentarem visões muito semelhantes no que tange ao conceito de crítica, tornando possível o estabelecimento do diálogo aqui proposto.

Palavras-chave: Tradução literária; Crítica; Criação; Antoine Berman; Marcel Proust.

\begin{abstract}
In this work we intend to reflect on fundamental concepts for Translation Studies, as well as for Literature in general, namely, creation, translation and criticism, under the perspective of Antoine Berman and Marcel Proust. As they are emblematic figures in their respective areas, which are interdependent, their conceptions have a certain canonicity and circulate in an expressive way in the literary milieu. Although Proust's and Berman's writings are about eighty years apart, it is possible to identify a series of conceptual confluences that attest to the modernity of Proust's thought about translation practice, in addition to presenting very similar views regarding the concept of criticism, making it possible to establish the dialogue proposed here.
\end{abstract}

Keywords: Literary translation; Criticism; Creation; Antoine Berman; Marcel Proust. 